\title{
Fermentation of various glycolytic intermediates and other compounds by rumen micro-organisms, with particular reference to methane production
}

\author{
BY J. W. CZERKAWSKI AND GRACE BRECKENRIDGE \\ Hannah Dairy Research Institute, Ayr
}

(Received I7 March I97I - Accepted 28 fune I971)

\begin{abstract}
I. Experiments with a small-scale artificial rumen have shown that of forty-two compounds tested the majority were fermented, as judged by the production of volatile fatty acids, but methane production was associated only with the fermentation of formate, certain hydroxyacids, pyruvic acid, primary alcohols (methanol, ethanol, propanol and butanol), glycerol and methyl compounds. With primary alcohols there was a stoichiometric relationship between methane production and the oxidation of the alcohols to the corresponding acids.

2. The fermentation of rhamnose and 1,2-propanediol was studied in detail. With both compounds there was a temporary accumulation of lactic acid and a continuous net production of propionic acid. The initial rate of acetate production was rapid with rhamnose but decreased subsequently, whereas propionate continued to increase. With propanediol the net rate of production of acetate was slow at first and then increased. There was no increase in the production of butyric acid with either rhamnose or propanediol, and the endogenous methane production was inhibited by $20-40 \%$. There was evidence for the formation of an unidentified compound during fermentation of thamnose and proparediol.
\end{abstract}

The fermentation characteristics of over twenty different carbohydrates were studied by Czerkawski \& Breckenridge (r969a), using an artificial rumen technique. With the exception of rhamnose, fermentation of the carbohydrates was associated with methane production and the amounts of methane produced were approximately proportional to the amounts of carbohydrates fermented. Sucrose and its constituent monosaccharides, glucose and fructose, were fermented rapidly with correspondingly rapid production of methane. Apart from the formation of the usual end-products of fermentation (e.g. volatile fatty acids, methane, carbon dioxide) other substances, such as microbial polysaccharides or lactic acid, accumulated initially and their concentration subsequently decreased.

Many other compounds occur in varying amounts in the diet of ruminant animals. Thus grasses contain varying amounts of dicarboxylic acids and several hydroxyacids, and sugar-beet contains relatively large proportions of these compounds together with citric acid. Methanol occurs in pectin, ethanol is a minor constituent of silages, and glycerol and choline are part of plant lipids (see Ranson \& Yeoman, 1961). Therefore, the studies with carbohydrates were extended to simpler compounds including organic acids, alcohols and some of the known intermediates in glycolysis. The dihydric alcohol I,2-propanediol is not an intermediate in glycolysis and does not normally occur in the ruminant diet, but it was included in the present studies because it is concerned in the microbial fermentation of rhamnose (Kluyver \& Schnellen, 1937) and it has been used as a food additive to counteract ketosis in cattle (Emery, Burg, Brown \& Blank, I964). 


\section{EXPERIMENTAL}

\section{Animals and diets}

Samples of rumen contents were obtained from two sheep given $45^{\circ} \mathrm{g}$ molassed sugar-beet pulp at 09.00 hours and 16.00 hours and $150 \mathrm{~g}$ hay at 16.00 hours. The samples of rumen contents, withdrawn before the morning feed through cannulas, were pooled and strained through four layers of gauze.

\section{Artificial rumen}

Small-scale apparatus. Most of the experiments were carried out in the small-scale artificial rumen described by Czerkawski \& Breckenridge (I970). In this apparatus up to twelve small samples of reaction mixture $\left(7^{-10} \mathrm{ml}\right)$ can be incubated in syringes, and the changes in the concentrations of various substances in both the liquid and the gas phase can be determined at the end of incubation. In the present experiments between eight and ten units were set up at any one time. Each syringe contained $7 \mathrm{ml}$ of reaction mixture prepared by mixing eight parts strained rumen contents with two parts artificial saliva (McDougall, I948) and containing the substance to be tested (listed in Tables 2-4) at a concentration of $4.0 \mathrm{mg} / \mathrm{ml}$ of reaction mixture. Each unit also contained $2 \mathrm{ml}$ of $5 \%(\mathrm{v} / \mathrm{v}) \mathrm{CO}_{2}$ in $\mathrm{N}_{2}$. Although the sheep were on constant rations, there was variation in the fermentative capacity of the rumen contents from day to day, and in each experiment, sucrose was also incubated under the same conditions to serve as a control. In each experiment a unit was included in which no substrate was added to allow for endogenous fermentation. The units were incubated for $4 \mathrm{~h}$ at $39^{\circ}$, and the concentrations of methane in the gas phase were measured.

Large-scale apparatus. The small-scale artificial rumen is not very precise and some experiments were repeated with the large-scale artificial rumen (Czerkawski $\&$ Breckenridge, $1969 b$ ), where much larger samples of rumen contents (100-200 ml) can be incubated in a closed system in which the gas is bubbled through the reaction mixture.

The details of experimental conditions are summarized in Table $\mathrm{I}$. In each experiment, two to five vessels were set up, each containing $200 \mathrm{ml}$ artificial saliva, $200 \mathrm{mg}$ $\left(\mathrm{NH}_{4}\right)_{2} \mathrm{CO}_{3}$, strained rumen contents $(\mathrm{I} 00-300 \mathrm{ml})$ and water to $500 \mathrm{ml}$, and in each experiment a control vessel was included, to which no substrate was added.

$U$ se of radioisotopes. The large-scale artificial rumen (Czerkawski \& Breckenridge, $\left.{ }^{\mathrm{I}} 969 \mathrm{~g}\right)$ was also used for experiments with $\left[\mathrm{I}^{14} \mathrm{C}\right]$ ethanol. The $\mathrm{CO}_{2}$ in the samples of gas was trapped in vials containing $1.0 \mathrm{ml} \times \cdot \circ \mathrm{M}-\mathrm{NaOH}$, the methane was burned by passing the gas through a tube at $900^{\circ}$ and the $\mathrm{CO}_{2}$ produced was trapped in alkali as above. The radioactivity was determined by adding $10 \mathrm{ml}$ of the scintillant developed by Bray (I960) and modified by British Drug Houses Ltd (Poole, Dorset). This contained $100 \mathrm{~g}$ naphthalene, $10 \mathrm{~g}$ PPO and $0.25 \mathrm{~g}$ POPOP in $\mathrm{I} 1$ dioxan. Aerosil (Bush, Beach \& Segner Bayley Ltd, London) was added (40 g/ 1 scintillant). The radioactivity was measured in a Nuclear Chicago counter (Unilux II) with an efficiency of about $80 \%$. The volatile fatty acids were separated by gas-liquid chromatography with an apparatus similar to the one described by James \& Martin (1952). The acids 
were titrated with phenolphthalein as an indicator ( $0.05 \%$ solution); the sodium salts of individual acids were taken to dryness, dissolved in $1.0 \mathrm{M}-\mathrm{NaOH}$ solution and the radioactivity was measured as described above. Phenolphthalein did not interfere; the efficiency of counting was $75 \%$.

\section{Table $\mathrm{I}$. Details of experiments with the large-scale artificial rumen}

(In each experiment each vessel contained $200 \mathrm{ml}$ artificial saliva (McDougall, I948), $200 \mathrm{mg}$ $\left(\mathrm{NH}_{4}\right)_{2} \mathrm{CO}_{3}$, strained rumen contents and water to total volume of $500 \mathrm{ml}$. The substrates were added in small volumes $(5-10 \mathrm{ml})$ of aqueous solutions. In Expt $\mathrm{C}$ the experimental vessel contained $8.7 \mathrm{mmol}\left[\mathrm{I}^{14} \mathrm{C}\right]$ ethanol with an activity of ro $\mu \mathrm{Ci}$ )

\begin{tabular}{|c|c|c|c|c|c|}
\hline & & \multicolumn{2}{|c|}{ Substrate } & \multirow[b]{2}{*}{$\begin{array}{c}\text { Duration } \\
\text { of } \\
\text { incubation } \\
\text { (h) }\end{array}$} & \multirow{2}{*}{$\begin{array}{l}\text { Concentra- } \\
\text { tion of } \\
\text { rumen } \\
\text { contents } \\
(\mathrm{ml} / \\
500 \mathrm{ml})\end{array}$} \\
\hline $\begin{array}{l}\text { Type of } \\
\text { expt }\end{array}$ & $\begin{array}{l}\text { No. of } \\
\text { expts }\end{array}$ & Type & $\begin{array}{c}\text { Initial } \\
\text { concentra- } \\
\text { tion } \\
(\mathrm{mg} / \mathrm{ml})\end{array}$ & & \\
\hline $\begin{array}{l}\text { son fermentation of } \\
\text { alcohols }\end{array}$ & 2 & $\begin{array}{l}\text { Methanol } \\
\text { Ethanol } \\
\text { Propanol } \\
\text { Butanol }\end{array}$ & $\begin{array}{l}4 \cdot 0 \\
4.0 \\
4 \cdot 0 \\
4 \cdot 0\end{array}$ & $0-6$ & 200 \\
\hline d-chain alcohols & $\mathbf{r}$ & $\begin{array}{l}\text { Isobutanol } \\
\text { Isopentanol }\end{array}$ & $\begin{array}{l}3 \cdot 0 \\
3 \cdot 0\end{array}$ & $0-8$ & 200 \\
\hline tion of radioactivity & I & {$\left[\mathrm{x}-{ }^{14} \mathrm{C}\right]$ ethanol } & 0.8 & $0-8$ & 300 \\
\hline ation of rhamnose and & $\mathbf{I}$ & $\begin{array}{l}\text { Sucrose } \\
\text { Rhamnose } \\
\text { Formate } \\
\text { Rhamnose + } \\
\text { formate }\end{array}$ & $\begin{array}{c}3.0 \\
3.0 \\
1.0 \\
3.0+0.5\end{array}$ & $0-5$ & 100 \\
\hline tion & 2 & 1,2-propanediol & $\begin{array}{l}1 \cdot 0 \\
2 \cdot 0\end{array}$ & $0-10$ & 200 \\
\hline
\end{tabular}

\section{Analytical methods}

The preparation of samples and the methods of analysis (carbohydrates, lactate) were described by Czerkawski \& Breckenridge $(1969 b)$. In addition, the concentrations of volatile fatty acids were determined by the method of Cottyn $\&$ Boucque ( 1968 ) and the concentration of propanediol was determined colorimetrically by the method of Jones \& Riddick (1957). The concentrations of lactate were determined by the method of Conway (1962). The gases were analysed by the chromatographic method of Czerkawski \& Clapperton (1968).

\section{RESULTS}

\section{Experiments with the small-scale artificial rumen}

The results, showing the effect of various substances on the production of acetic, propionic and butyric acids and methane, are summarized in Tables 2-4.

\section{Aliphatic acids (Table 2)}

As expected, the incubation of formate with rumen contents resulted in considerable increase in production of methane, but the other monocarboxylic acids contributed little to either methane production or fermentation. There was no increase in the methane production with any of the dicarboxylic acids tested and, in fact, three 
acids (oxalic, glutaric and adipic) appeared to inhibit the endogenous methane production.

There was a significant increase in production of acetic acid when malonic acid was incubated with rumen contents and there was a considerable increase in the production of both acetic and propionic acids with succinate. The incubation of the unsaturated dicarboxylic acids (fumaric and maleic) resulted in an increase in propionic acid only.

Table 2. Changes in the production of acetate, propionate, butyrate and methane during incubation of aliphatic acids with rumen contents

(The results are expressed as an increase relative to endogenous fermentation $(+)$ compared with production from sucrose taken as +100 . The negative values represent a decrease compared with the endogenous fermentation. Each value is the mean valuc for the number of experiments given in parentheses)

\begin{tabular}{|c|c|c|c|c|}
\hline Substance & Acetate & Propionate & Butyrate & Methane \\
\hline Formic (2) & +10 & +4 & +5 & +204 \\
\hline Acetic (z) & . & +16 & +23 & +3 \\
\hline Propionic (4) & -10 & . & +6 & -5 \\
\hline Butyric (2) & -17 & +7 & . & $+r$ \\
\hline Valeric (r) & -3 & +16 & +9 & -3 \\
\hline Caproic (I) & $-2 I$ & +15 & -23 & +3 \\
\hline Oxalic (2) & $-\mathrm{I}_{2}$ & $+\mathrm{I}_{3}$ & +12 & -24 \\
\hline Malonic (4) & +37 & +17 & -2 & -3 \\
\hline Succinic (3) & $+\mathbf{1 8 8}$ & +199 & $+2 I$ & -6 \\
\hline Glutaric (I) & -23 & +10 & - I0 & $-2 I$ \\
\hline Adipic (I) & +22 & $+\mathrm{T}$ & -6 & -20 \\
\hline Maleic (2) & $-I I$ & $+3 x$ & -8 & -12 \\
\hline Fumaric (2) & -10 & +93 & -23 & -8 \\
\hline
\end{tabular}

Values in bold-face type are discussed at length in the text.

\section{Hydroxy-acids and carbonyl compounds (Table 3)}

The fermentation of lactic, glyceric, tartaric, malic and pyruvic acids was associated with a net increase in methane production. The addition of acetaldehyde and glyceraldehyde resulted in the inhibition of methane production. Lactic acid was converted into propionic acid and apparently into butyric acid but, since butyric acid has a retention volume on gas-liquid chromatography almost indistinguishable from that of acrylic acid, it is possible that lactic acid was converted only into propionic and acrylic acids. The fermentation of the isomer acid ( $\beta$-OH-propionic acid) resulted in the production of both acetic and propionic acids but this substrate inhibited the production of butyric acid. There was a large increase in acetic acid production with all three hydroxy-dicarboxylic acids, and there was an increase in propionic acid concentration with malic acid only. Both acetaldehyde and pyruvic acid led to considerable increases in acetic acid production.

\section{Alcohols, polyalcohols and methyl compounds (Table 4)}

The fermentation of all the primary alcohols up to and including butanol was associated with a considerable increase in methane production. The amounts of 
Table 3. Changes in the production of acetate, propionate, butyrate and methane during incubation of hydroxy-acids and carbonyl compounds with rumen contents ( full explanation in Table 2)

\begin{tabular}{|c|c|c|c|c|}
\hline Substance & Acetate & Propionate & Butyrate & Methane \\
\hline Glycollic (I) & -4 & +8 & +13 & -16 \\
\hline Lactic (4) & +18 & +28 & +45 & +34 \\
\hline$\beta$-OH-propionic (4) & +29 & +34 & $-6 \mathbf{I}$ & +8 \\
\hline$\beta-\mathrm{OH}$-isovaleric (I) & $+2 \mathrm{I}$ & -3 & -4 & -7 \\
\hline Glyceric (4) & +12 & +4 & +37 & +35 \\
\hline Quinic (1) & -2 & +2 & -2 & $-\mathbf{I I}$ \\
\hline Tartronic (2) & +73 & -4 & +12 & -20 \\
\hline Tartaric (2) & $+\mathbf{2 I}$ & $-r_{3}$ & +4 & +37 \\
\hline Malic (2) & +43 & $+\mathbf{1 3 0}$ & -8 & +19 \\
\hline Citric (I) & +69 & +42 & $-I_{3}$ & +10 \\
\hline Acetaldehyde (2) & +105 & -15 & -33 & $-7 I$ \\
\hline Glyceraldehyde (2) & -12 & -8 & +18 & -29 \\
\hline Acetone (I) & -8 & -9 & -7 & +9 \\
\hline Acetol (I) & +24 & -7 & $+x_{3}$ & +13 \\
\hline Pyruvic (z) & $+9 \mathbf{I}$ & +9 & t ro & +32 \\
\hline
\end{tabular}

Values in bold-face type are discussed at length in the text.

'Table 4. Changes in the production of acetate, propionate, butyrate and methane during incubation of alcohols, polyalcohols and methyl compounds with rumen contents (full explanation in Table 2)

\begin{tabular}{|c|c|c|c|c|}
\hline Substance & Acetate & Propionate & Butyrate & Methane \\
\hline Methanol (3) & +17 & +6 & +6 & $+x 73$ \\
\hline Ethanol (2) & $+\mathbf{5 3}$ & -8 & -5 & +98 \\
\hline Propanol (3) & +19 & +79 & +3 & +59 \\
\hline Butanol (2) & +12 & -6 & +73 & +68 \\
\hline Pentanol (I) & +8 & +9 & +8 & $+\mathbf{I}$ \\
\hline Hexanol (I) & -63 & -23 & $+\mathrm{II}$ & -100 \\
\hline $\begin{array}{l}\text { Isopropanol (2) } \\
\text { Secondary butanol (I) }\end{array}$ & -33 & +23 & -5 & $\begin{array}{l}+15 \\
+25\end{array}$ \\
\hline Secondary butanol (I) & & -3 & +7 & $+2 I$ \\
\hline $\begin{array}{l}\text { Glycerol (2) } \\
\text { I,2-Propanediol (7) } \\
\text { I,3-Propanediol (2) }\end{array}$ & $\begin{array}{l}+18 \\
+23 \\
+68\end{array}$ & $\begin{array}{l}+44 \\
+83 \\
+18\end{array}$ & $\begin{array}{r}+29 \\
+3 \\
-19\end{array}$ & $\begin{array}{r}+25 \\
-\mathbf{r} 3 \\
-5\end{array}$ \\
\hline Rhamnose (4) & $+4 x$ & $+6 I$ & +9 & -5 \\
\hline Methionine ( $\mathrm{r}$ ) & -17 & $+x 8$ & +2 & +29 \\
\hline Choline (2) & +7 & +13 & +3 & +73 \\
\hline
\end{tabular}

Values in bold-face type are discussed at length in the text.

methane produced when methanol was added were greater than with ethanol, propanol or butanol. n-Pentanol did not affect methane production and hexanol seemed to inhibit fermentation. The incubation of glycerol, isopropanol, secondary butanol and the methyl compounds (methionine and choline) resulted in an increase in the production of methane. The primary alcohols appeared to be converted into the corresponding acids, but the fermentation of glycerol resulted in net production of all three volatile fatty acids. With I,2-propanediol there was an increase in the production of volatile fatty acids, the largest increase being in that of propionic acid. As shown 
before (Czerkawski \& Breckenridge, r969a), rhamnose gave no methane, but was fermented to give a considerable increase in propionic acid and a small increase in acetic acid. It should be noted that the fermentation of both propanediol and rhamnose was accompanied by the production of a characteristic odour reminiscent of certain allin compounds. This was not observed with any other compounds tested.

\section{Experiments with large-scale artificial rumen}

\section{Oxidation of alcohols}

The experimental details are summarized in Table I(A), and the results of two experiments are summarized in Table 5 . No accumulation of hydrogen was observed, and the concentration of lactic acid in the experimental vessels was low and not significantly different from that in the controls. The only measurable changes that occurred were in the production of methane and volatile fatty acids.

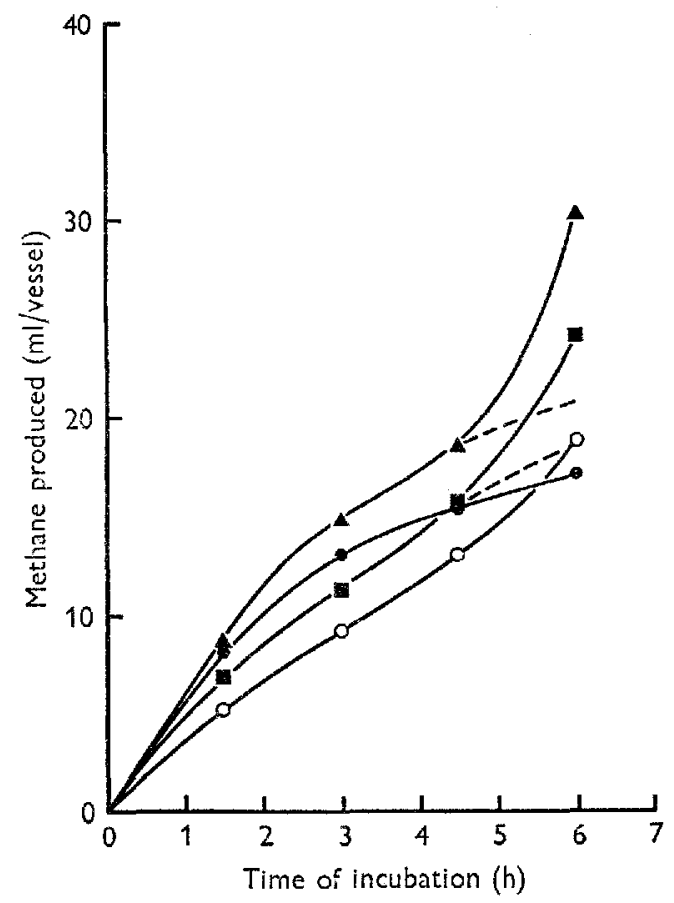

Fig. I. Methane production during incubation of methanol (O), ethanol (e), propanol (A) and butanol ( $\mathbf{0}$ ) with strained rumen contents in the artificial rumen. The dotted lines show a possible course of methane production if the rates continued to decrease regularly.

As can be inferred from Table 5 , the estimation of the rates of production of volatile fatty acids was subject to considerable error. Nevertheless, the results show quite clearly that the fermentation of various alcohols was associated with the production of the corresponding acids only. Methane production was linear with time only with methanol; with the other alcohols the rate tended to decrease up to $4-5 \mathrm{~h}$ of incubation, but with propanol and butanol the rate usually tended to increase subsequently. 
The results of one experiment illustrating this are shown in Fig. I. The molar ratios of the rates of production of methane and volatile fatty acids are shown in the last column in Table 5 . The mean values approach the value of 2.0 and imply that the production of I mol methane was associated with the oxidation of $2 \mathrm{~mol}$ of the corresponding acid. The apparent oxidation of alcohols to the corresponding acids was investigated further by incubating n-butanol, isobutanol, $\mathrm{n}$-pentanol and isopentanol with rumen contents (Table IB). Neither n-pentanol nor isopentanol resulted in an increase in methane, although ethanol in the same experiment produced an increase in the rate of formation of both methane and acetic acid (67

Table 5. Mean rates with their standard errors of production ( $\mu$ moll $/ h$ ) of volatile fatty acids (VFA) and methane during incubation of alcohols with rumen contents

\begin{tabular}{|c|c|c|c|c|c|c|}
\hline \multirow[b]{2}{*}{$\begin{array}{c}\text { Expt } \\
\text { no. }\end{array}$} & & \multicolumn{3}{|c|}{ VFA } & & \multirow[b]{2}{*}{$\begin{array}{l}\text { Ratio, } \\
\text { VFA: } \\
\mathrm{CH}_{4}\end{array}$} \\
\hline & Substrate & Acetate & Propionate & Butyrate & Methane & \\
\hline I & $\begin{array}{l}\text { Methanol } \\
\text { Ethanol } \\
\text { Propanol } \\
\text { Butanol }\end{array}$ & $\begin{array}{r}0 \pm 5 \\
+202 \pm 51 \\
+11 \pm 10 \\
+9 \pm 15\end{array}$ & $\begin{array}{c}+10 \pm 10 \\
-21 \pm 9 \\
+2 x 0 \pm 12 \\
-22 \pm 13\end{array}$ & $\begin{array}{c}+5 \pm 5 \\
+20 \pm 11 \\
-12 \pm 8 \\
+162 \pm 31\end{array}$ & $\begin{array}{r}+105 \pm 14 \\
+87 \pm 17 \\
+121 \pm 31 \\
+112 \pm 20\end{array}$ & $\begin{array}{l}\cdot \\
2 \cdot 3 \\
I \cdot 8 \\
I \cdot 5\end{array}$ \\
\hline & & & & & \multicolumn{2}{|c|}{ Mean $x \cdot 9$} \\
\hline 2 & $\begin{array}{l}\text { Methanol } \\
\text { Ethanol } \\
\text { Propanol } \\
\text { Butanol }\end{array}$ & $\begin{array}{c}+30 \pm 9 \\
+\mathrm{r2I} \pm \mathbf{3 I} \\
-\mathrm{I} 3 \pm 7 \\
+7 \pm \mathrm{II}\end{array}$ & $\begin{array}{r}-21 \pm 9 \\
-17 \pm 8 \\
+141 \pm 13 \\
-22 \pm 15\end{array}$ & $\begin{array}{c}-3 \pm 3 \\
+9 \pm 8 \\
-5 \pm 8 \\
+157 \pm 28\end{array}$ & $\begin{array}{r}+116 \pm 5 \\
+67 \pm 9 \\
+85 \pm 7 \\
+81 \pm 5\end{array}$ & $\begin{array}{l}\cdot \\
I \cdot 8 \\
I \cdot 7 \\
I \cdot 9\end{array}$ \\
\hline
\end{tabular}

In Expt $I$ each value is the mean of four determinations and in Expt 2 each value is the mean of six determinations.

Values in bold-face type are for the volatile fatty acids derived from the added alcohols.

The negative values indicate that the rates were smaller than the rates obtained in incubations for the controls.

and $159 \mu \mathrm{mol} / \mathrm{h}$ respectively). Isobutanol did not give rise to as much methane $(55 \mu \mathrm{mol} / \mathrm{h})$ as did $\mathrm{n}$-butanol (I $6 \mu \mathrm{mol} / \mathrm{h}$ ), but nevertheless the fermentation of isobutanol was associated with the production of small but significant amounts of isobutyric acid (3I $\mu \mathrm{mol} / \mathrm{h})$.

\section{Fermentation of $\left[{ }^{1}-{ }^{14} \mathrm{C}\right]$ ethanol}

The control vessel contained water and the experimental vessel contained $8.7 \mathrm{mmol}$ $\left[{ }^{1}-{ }^{14} \mathrm{C}\right]$ ethanol (Io $\mu \mathrm{Ci}$ ) (Table $\mathrm{IC}$ ). This should have given $44500 \mathrm{~d} / \mathrm{min}$ per $\mathrm{ml}$ reaction mixture, and throughout the incubation of $8 \mathrm{~h}$ the radioactivity in solution did not increase or decrease regularly, the mean radioactivity being $44 \mathrm{IOO} \mathrm{d} / \mathrm{min}$ per $\mathrm{ml}$. The mean net rate of production of methane was $48 \mu \mathrm{mol} / \mathrm{vessel}$ per $\mathrm{h}$ and the net productions of acetate, propionate and butyrate were respectively $+1 \mathrm{I} 2,-2$ and +3 $\mu \mathrm{mol} / \mathrm{vessel}$ per h, i.e. $2 \cdot 3 \mathrm{~mol}$ acetate $/ \mathrm{mol}$ methane. The extent of labelling of acetate, propionate, butyrate and the particulate matter is shown in Fig. 2. Clearly, the labelling of acetate was much greater than the labelling of the other components. 
After $8 \mathrm{~h}$ of incubation the radioactivity in acetate was $375^{\circ} \mathrm{d} / \mathrm{min}$ per $\mathrm{ml}$. Thus $8.5 \%$ of the radioactivity in the ethanol was converted into radioactivity in the form of acetate. This was equivalent to $73^{\circ} \mu \mathrm{mol}$ ethanol/vessel or $9 \mathrm{x} \mu \mathrm{mol} / \mathrm{vessel}$ per $\mathrm{h}$ and agreed fairly well with the measured total acetate production and twice the rate of methane production ( $\mathrm{I}$ I 2 and $96 \mu \mathrm{mol}$ vessel/per $\mathrm{h}$ respectively).

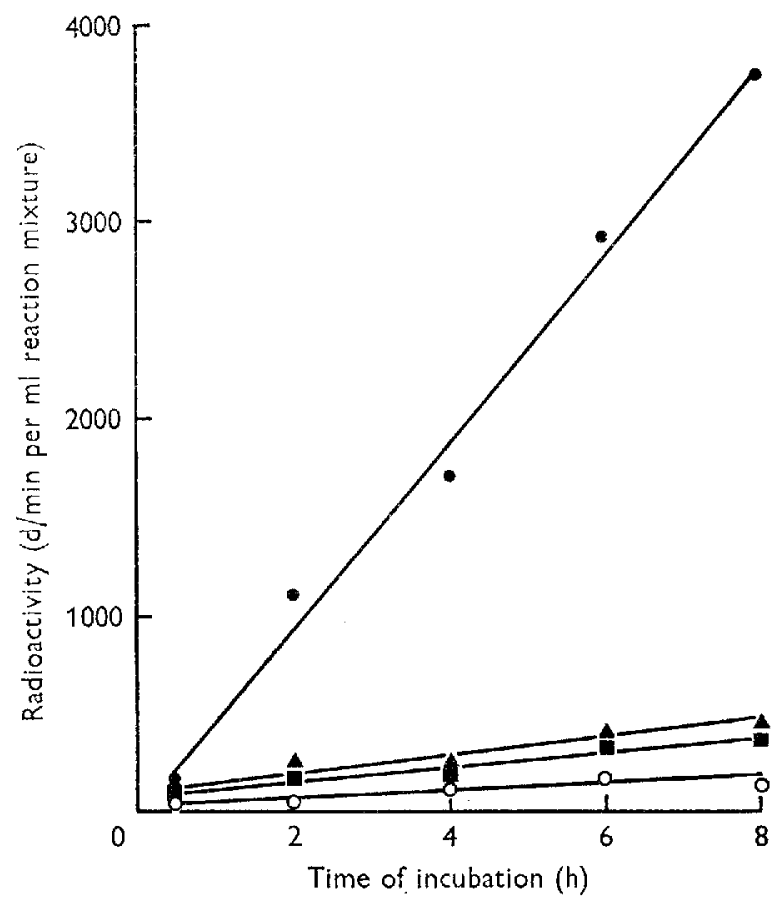

Fig. 2. Incorporation of radioactivity in acctate (@), propionate $(\boldsymbol{\Delta})$, butyrate $(\boldsymbol{C})$ and particulate matter $(O)$, during incubation of $\left[\mathrm{I}-{ }^{14} \mathrm{C}\right]$ ethanol with strained rumen contents.

Table 6. Radioactivity in various substances after incubation of $\left[\mathrm{I}^{14} \mathrm{C}\right]$ ethanol with rumen contents for $8 \mathrm{~h}$

$\begin{array}{llcc} & & \mathrm{d} / \mathrm{min} \text { per } \mathrm{ml} & \% \\ \text { Added radioactivity } & \ldots & 44500 & 100 \\ \text { Suspension } & & 44100 & 99 \\ \text { Acetate } & & 3750 & 8.40 \\ \text { Propionate } & 432 & 0.97 \\ \text { Butyrate } & 398 & 0.89 \\ \text { Particulate matter } & & 370 & 0.83 \\ \mathrm{CO}_{2} \text { gas } & 30 & 0.07 \\ \mathrm{CH}_{4} & & 67 & 0.15\end{array}$

The radioactivity in $\mathrm{CO}_{2}$ and methane in the gas phase was small and did not tend to increase during the incubation, the mean values being 30 and $67 \mathrm{~d} / \mathrm{min}$ per $\mathrm{ml}$ reaction mixturc. The recoveries of radioactivity in various products after $8 \mathrm{~h}$ of incubation are shown in Table 6 . Neither methane nor $\mathrm{CO}_{2}$ - the accepted precursor of methane - were labelled to any significant extent. 


\section{Fermentation of rhamnose and $\mathrm{I}, 2$-propanediol}

Rhamnose. It was shown by Czerkawski \& Breckenridge ( $1969 a$ ) that the fermentation of rhamnose was not associated with methane production. In the present work the fermentation of propanediol resulted in a small but consistent inhibition of the endogenous methane production. This was investigated further by incubating rhamnose in a reaction mixture in which the methane production (but not the production

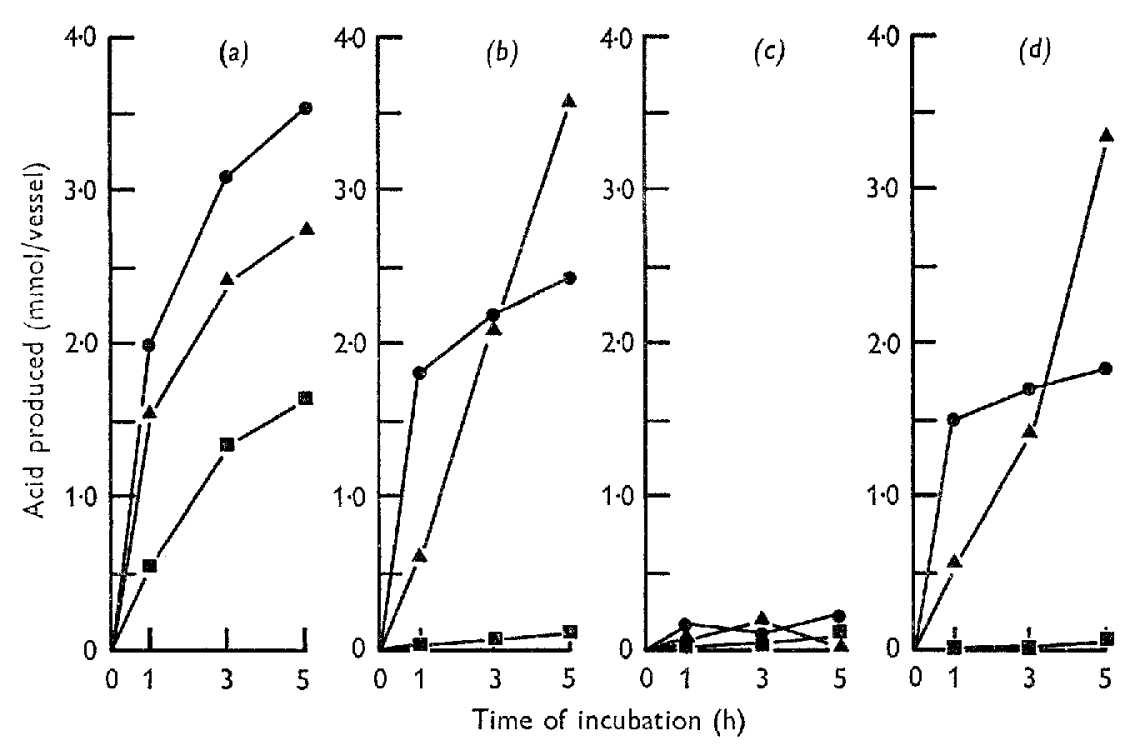

Fig. 3. Production of acetic ( $)$, propionic $(\boldsymbol{A})$, and butyric ( $\mathbf{B}$ ) acids during incubation of sucrose $(a)$, rhamnose $(b)$, formate $(c)$ and mixture of rhamnose and formate $(d)$, with strained rumen contents.

of volatile fatty acids) was increased by adding formate (Table ID). The production of acetic, propionic and butyric acids is shown in Fig. 3. With sucrose all three acids were produced rapidly at first, but thereafter the rate decreased steadily. There was virtually no butyrate produced with rhamnose, the rapid initial rate of production of acetate tended to decrease and the rate of production of propionate increased steadily throughout incubation. As was to be expected, with formate as substrate the changes in the concentrations of volatile fatty acids were not significantly different from the control values. When rhamnose was fermented in the presence of formate the curves were qualitatively similar to those obtained when rhamnose was fermented alone, but all the values were somewhat lower.

It can be seen from Fig. 4 that there was rapid methane production with both sucrose and formate, and that the rates decreased when the substrates were exhausted. Rhamnose inhibited both the endogenous methane production (by about $40 \%$ ) and the methane production due to formate (by about $30 \%$ ). There was a temporary accumulation of $\mathrm{H}_{2}$ with formate and this was smaller with formate and rhamnose, in spite of the fact that an inhibition of $10 \mathrm{ml}$ of methane would result in a saving of 
$40 \mathrm{ml} \mathrm{H}_{2}$. The lactate concentration increased after $\mathrm{I} h$ to $2 \cdot 3 \mathrm{mmol} /$ vessel when both sucrose and rhamnose were fermented. It soon decreased with sucrose until at the end of incubation it was only slightly greater than the small control value. With rhamnose it remained near $2 \mathrm{mmol} / \mathrm{vessel}$ and decreased more slowly towards the end of incubation (Table 7). It can be seen also that with rhamnose there was a small inhibi-

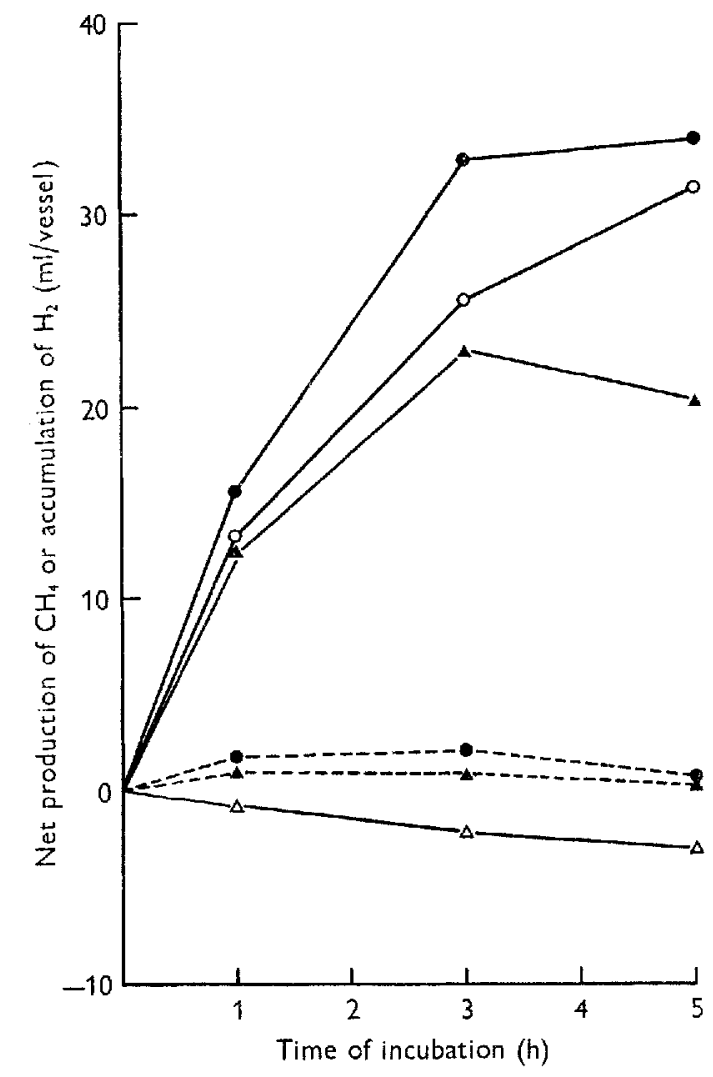

Fig. 4. Production of methane and accumulation of hydrogen during incubation of sucrose (O), formate $(\boldsymbol{O})$, rhamnose $(\Delta)$ and mixture of rhamnose with formate $(\Delta)$ with strained rumen contents. The curves showing accumulation of hydrogen are drawn in broken lines.

Table 7. Net increases in the concentrations of lactate, formate and microbial polysaccharide and the concentration of soluble carbohydrate at the end of incubation of rumen contents with sucrose, rhamnose, formate and rhamnose + formate (mmol/vessel)

(The starting amounts of sucrose, rhamnose and formate were $4 \cdot 38,8 \cdot 20$ and $7 \cdot 35 \mathrm{mmol}$ / vessel respectively. The concentrations of soluble carbohydrate and polysaccharide are given in terms of hexose)

Substrate

Sucrose

Rhamnose

Formate

Rhamnose + formate
Lactate

0.10

0.82

$-0.03$

0.65
Formate

0.07

0.06

0.66

$\mathrm{I} \cdot \mathrm{O}_{3}$
Soluble

Polysaccharide carbohydrate

$\begin{array}{ll}0.91 & 0.20 \\ 0.09 & 1.05 \\ 0.00 & 0.00 \\ 0.24 & 0.98\end{array}$


tion of the fermentation of formate $(5 \%)$. With formate only, the amount of formate used was $6.69 \mathrm{mmol}$, of which $0 . \mathrm{I}$ mmol was used in production of $\mathrm{H}_{2}$. Therefore the amount of methane formed ( $\mathrm{mol} / \mathrm{mol}$ formate) was $\mathrm{I}_{5} \cdot 5 / 6 \cdot 59=0.23$, an amount very close to the theoretical value of 0.25 (Carrol \& Hungate, 1955). When rhamnose was also present the amount of methane formed ( $\mathrm{mol} / \mathrm{mol}$ formate) was only o.I4.

Table 8. Recovery of carbon in volatile fatty acids, lactate, methane, carbon dioxide, formate, polysaccharide and unreacted substrates during incubation of sucrose, rhamnose and formate with rumen contents ( $\%$ of added substrate carbon)

$\begin{array}{ccccc}\begin{array}{c}\text { Period of } \\ \text { incubation (h) }\end{array} & \text { Sucrose } & \text { Rhamnose } & \text { Formate } & \begin{array}{c}\text { Rhamnose } \\ \text { + formate }\end{array} \\ \text { I } & 55 & \text { II } 2 & 74 & 102 \\ 3 & 58 & 82 & 55 & 76 \\ 5 & 69 & 56 & 32 & 51\end{array}$
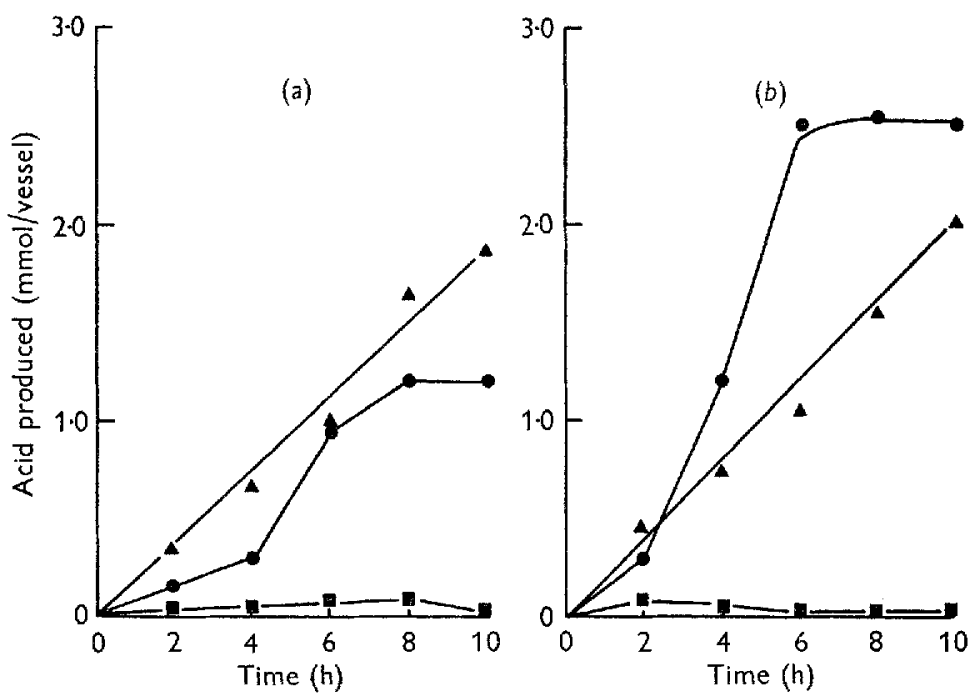

Fig. 5. Production of acetic ( $)$, propionic (A) and butyric (\$) acids during incubation of $500 \mathrm{mg}(a)$ and $1000 \mathrm{mg}(b)$ of I,2-propanediol with rumen contents.

There was some increase in the formation of polysaccharide from rhamnose in the presence of formate, but this was small compared with the amount of substrate fermented. It can be seen from Table 7 that sucrose was used completely ( $98 \%$ ) by the end of the incubation but about $13 \%$ of rhamnose remained. The concentration of rhamnose decreased linearly during incubation. The mean rates of removal of rhamnose were $\mathrm{I} .57$ and $\mathrm{I} .56 \mathrm{mmol} / \mathrm{vessel}$ per $\mathrm{h}$ with rhamnose and rhamnose in presence of formate respectively.

The recoveries of carbon calculated from the net increases in known products and unreacted substrates are summarized in Table 8 . The recovery of carbon with sucrose was low at first and tended to increase to the values of $70-80 \%$ found previously (Czerkawski \& Breckenridge, r $969 a$ ). The recovery of carbon with rhamnose, with or without formate, was high initially and then decreased to about $50 \%$. 
Propanediol. Preliminary experiments, in which the concentration of strained rumen contents was $100 \mathrm{ml} / 500 \mathrm{ml}$ reaction mixture, resulted in only small increases in the concentration of volatile fatty acids or lactate. Therefore in subsequent experiments the concentration of rumen contents was increased (Table I E). Some of the results are summarized in Fig. 5, where the net production of volatile fatty acids is given. As
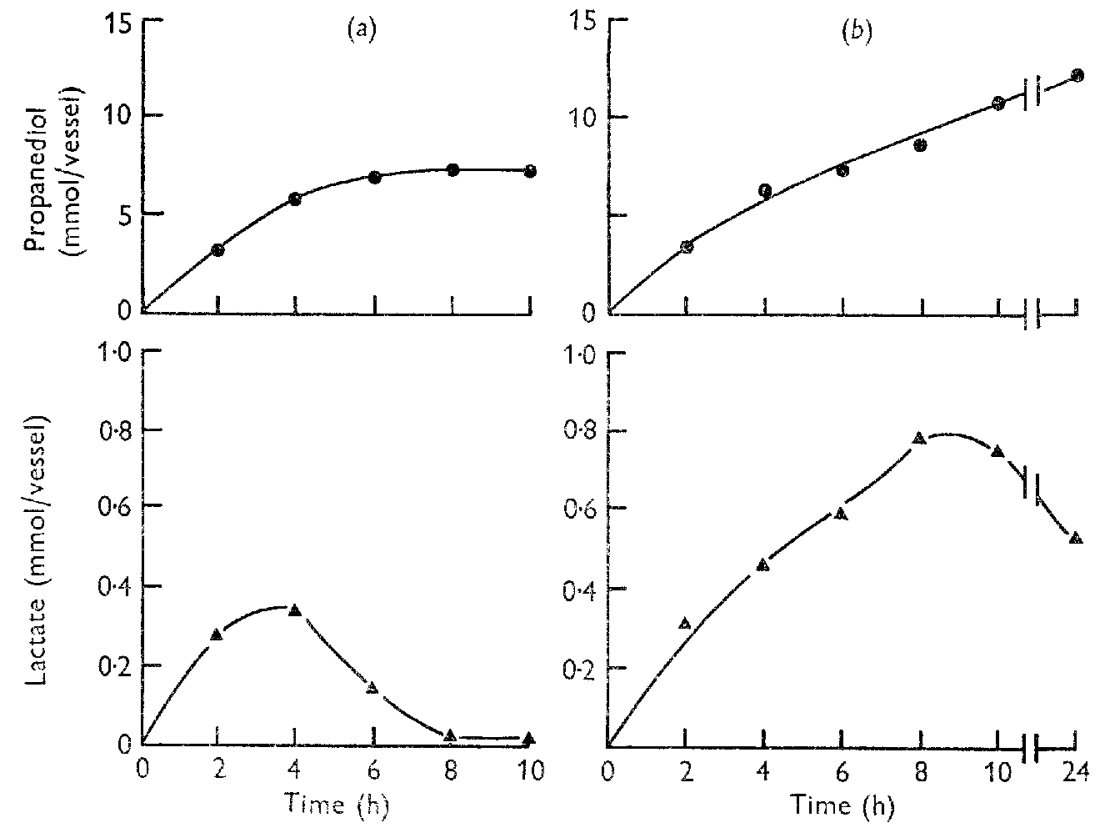

Fig. 6. Utilization of the substrate (6) and production of lactic acid (A) during incubation, $500 \mathrm{mg}(a)$ and $1000 \mathrm{mg}(b)$, of propanediol with rumen contents.

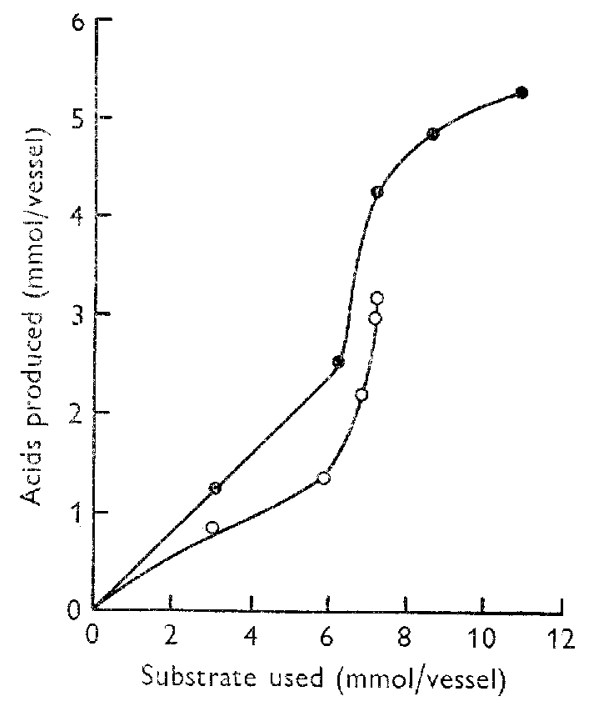

Fig. 7. Production of acetic + propionic + butyric + lactic acids as function of substrates used during incubation of $500 \mathrm{mg}(\mathrm{O})$ and $1000 \mathrm{mg}(0)$ of propanediol with rumen contents. 
with rhamnose, no significant amount of butyric acid was produced and the concentration of propionic acid increased steadily. Moreover, the concentration of propionic acid continued to increase although all the propanediol was used up after $4-6 \mathrm{~h}$ of incubation (Fig. $5^{a}$ ). The increase in the concentration of acetic acid was small initially and became greater during the course of incubation, but unlike propionic acid the production of acetic acid tended to slow down before the end of incubation, whether there was any substrate left or not. The production of propionic acid was largely independent of the concentration of propanediol, and the production of acetic acid increased with the concentration of substrate.

It can be seen in Fig. 6 that lactate was a possible intermediate in conversion of propanediol into propionate or acetate. In fact, when the incubation was continued the concentration of lactate in the vessel with high concentration of propanediol decreased. The utilization of the substrate is also shown in Fig. 6; clearly the rate did not depend on the concentration of substrate. In agreement with previous findings, addition of propanediol resulted in the inhibition of endogenous methane production. With the lower concentration of propanediol the inhibition was 22 and $34 \%$ after 3 and $6 \mathrm{~h}$ of incubation respectively. With the higher concentration of propanediol the inhibition was 32 and $35 \%$ respectively.

The recovery of carbon was low and ranged from about $30 \%$ at the beginning of incubation to about $50 \%$ at the end. As shown in Fig. 7 , the rate of incrcase in the concentration of measured acids per unit concentration of substrate utilized increased rapidly when about $6 \mathrm{mmol}$ substrate had been used. The slopes of the curves increased from about $0 \cdot 2$ to about $2 \cdot 0$. Thus the rate of production of volatile fatty acids and lactic acid was greater than the rate of utilization of substrate. This suggested production and subsequent utilization of an intermediate compound that was not estimated by the present method.

\section{DISCUSSION}

\section{Simple substrates}

It can be seen from the results of experiments with the small-scale artificial rumen that the amounts of end-products formed varied with various simple substrates. With monocarboxylic aliphatic acids, only formate appeared to be a source of methane, and the increase in butyric acid production when acetate was a substrate indicated some conversion of acetate into butyrate. The dicarboxylic acids in general inhibited methane production although some of them were fermented extensively, mainly to propionic acid. It is significant that these are the acids that are involved in the pathway of conversion of pyruvic acid into propionic acid (succinate, fumarate).

It seemed initially that one of the prerequisites for methane production was that the substrates should contain a hydroxyl group in the $\alpha$-position (lactic, glyceric, tartaric and malic acids). However, glycollic and tartronic acids in fact resulted in an inhibition of endogenous methane production. The aldehydes also inhibited methane production, the ketones had no effect and, as expected (Demeyer \& Henderickx, r967), pyruvic acid was a good source of methane. 
The compounds whose fermentation resulted in the production of large amounts of propionic acid could be divided into two groups: those that gave rise to methane as well as propionate (lactic and malic acid, propanol, glycerol and methionine) and those that gave rise to propionate but gave no methane or even inhibited endogenous methane production (succinic, maleic and fumaric acids, propanediol and rhamnose). However, this division is probably artificial. Lactic and malic acids and glycerol are related inasmuch as they are readily convertible into pyruvate and give moderate amounts of acetate, but the fermentation of propanol should be classed with those of the other primary alcohols. In this connexion, Sijpesteijn \& Elsden (I952) showed that the fermentation of succinate resulted in the increase in propionic acid but inferred from uptake of hydrogen that there was methane production. Similarly it is difficult to see any direct metabolic involvement in succinic, maleic and fumaric acids on the one hand and rhamnose and propanediol on the other.

\section{'Oxidation' of alcohols}

The comparative work with the large-scale artificial rumen showed quite conclusively that methanol, ethanol, propanol and butanol were oxidized to the corresponding acids, presumably according to the equation

$$
\text { R. } \mathrm{CH}_{2} \mathrm{OH}+\mathrm{H}_{2} \mathrm{O} \rightarrow \mathrm{R} . \mathrm{COOH}+2 \mathrm{H}_{2} \text {, }
$$

and that the resulting hydrogen was used (by other micro-organisms) for methane production according to the equation

$$
\mathrm{CO}_{2}+{ }_{4} \mathrm{H}_{2} \rightarrow \mathrm{CH}_{4}+2 \mathrm{H}_{2} \mathrm{O},
$$

giving $2 \mathrm{R} \cdot \mathrm{CH}_{2} \mathrm{OH}+\mathrm{CO}_{2} \rightarrow 2 \mathrm{R} . \mathrm{COOH}+\mathrm{CH}_{4}$.

Thus, one would expect the formation of $2 \mathrm{~mol} \mathrm{acid} / \mathrm{mol}$ methane and the values found were close to that value. It is possible that methanol follows the same pathway, but since the product, formic acid, results in considerable methane production it does not accumulate and additional amounts of methane are formed instead.

The conclusion that the alcohols are converted into the corresponding acids without cleavage was confirmed, at least with ethanol, by incubating $\left[{ }^{I}-{ }^{14} \mathrm{C}\right]$ ethanol with rumen contents. The radioactivity was incorporated almost entirely in the acetic acid, and only negligibly small amounts of radioactivity were found in methane or carbon dioxide.

\section{Fermentation of rhamnose and propanediol}

Little is known about the microbial metabolism of rhamnose in general and virtually nothing is known about its metabolism in the rumen. Rhamnose does not occur in large quantities in nature but its occurrence is widespread, particularly in plant tissues. Kluyver \& Schnellen (1937) showed that certain bacilli converted rhamnose into acetate, succinate and I,2-propanediol. This and subsequent work (e.g. Takagi \& Sawada, 1964) showed that lactaldehyde might be an intermediate, and it is now accepted that rhamnose is dissimilated by the following pathway:

$$
\begin{gathered}
\text { rhamnose } \rightarrow \text { rhamnulose } \rightarrow \text { rhamnulose- }-\mathrm{P} \rightarrow \text { lactaldehyde }+ \\
\text { dihydroxyacetone phosphate. }
\end{gathered}
$$


Lactaldehyde may be converted into I,2-propanediol (Scardovi, 1960), and dihydroxyacetone may subsequently be converted into pyruvic acid to give acetate and hydrogen (which might be necessary for the production of propanediol) or succinate (through oxaloacetate, malate and fumarate). No succinic acid could be detected when thamnose was incubated with the rumen micro-organisms, but succinic acid is readily fermented, giving both propionic and acetic acids and, significantly, very little butyric acid and no methane. Little is known about the fate of the lactaldehyde fragment of rhamnose. It is possible that it is initially oxidized to lactic acid (cf. accumulation of lactic acid during fermentation) and that the lactic acid is subsequently converted into acrylic and propionic acids by the so-called direct reductive pathway. Moreover, a proportion of lactic acid might be converted into pyruvic acid and give more propionic acid and smaller amounts of acetic acid.

In the initial stages of incubation of rhamnose with rumen contents the predominant products were acetic and lactic acids. This should have resulted in the generation of considerable reducing power, and it can be calculated that between 80 and $100 \mathrm{ml}$ of hydrogen should have accumulated or $20-25 \mathrm{ml}$ methane should have been produced. There was no accumulation of hydrogen gas and the methane production was less than in the control vessels. During the latter part of the incubation lactate concentration decreased and the small increase in acetic acid was accompanied by large increases in the concentration of propionic acid. It can be shown that there was net requirement for hydrogen during this stage of reaction and it is possible that hydrogen accumulated initially in bound form, to be used in later stages of fermentation.

Although 1,2-propanediol is simpler than rhamnose, its fermentation pattern was not simple. If it can be assumed that propanediol is initially converted into lactaldehyde, it might well share in the metabolic pathways of rhamnose. Thus, as with rhamnose, little or no butyric acid was produced, and there was a temporary accumulation of lactate. The propionate production with propanediol was also similar to propionate production with rhamnose, but acetate production was different. After $4 \mathrm{~h}$ of incubation the rates of production of acetic, propionic and lactic acids were greater than the rates of utilization of propanediol. This implied the formation of an unidentified compound. Furthermore the fermentation of both rhamnose and propanediol resulted in the production of a characteristic odour. This appeared within 5-10 min after the start of incubation and increased in intensity, but disappeared when the substrate was exhausted (e.g. in the experiment given in Fig. 7 a). Clearly, much more work is required, particularly with pure or enriched cultures of those rumen microorganisms that appear to convert substrates like propanediol or rhamnose into propionic acid. An ability to increase propionate production at the expense of acetate and butyrate, together with a small but significant inhibition of methane production without accumulation of hydrogen, could be of considerable practical interest. 


\section{REFERENCES}

Bray, G. A. (1960). Analyt. Biochem. ז, 279.

Carrol, E. J. \& Hungate, R. E. (1955). Archs Biochem. Biophys. 56, 525.

Conway, E. J. (1962). Microdiffusion Analysis and Volumetric Error p. 234. London: Crosby, Lockwood and Son Ltd.

Cottyn, B. G. \& Boucque, C. V. (1968). J. agric. Fd Chem. I6, 105.

Czerkawski, J. W. \& Breckenridge, G. (rg69a). Br. F. Nutr. 23, 925.

Czerkawski, J. W. \& Breckentidge, G. (1969b). Br. F. Nutr. 23, 5 I.

Czerkawski, J. W. \& Breckenridge, G. (I970), Lab. Pract. 19, 7 I7.

Czerkawski, J. W. \& Clapperton, J. L. (1968). Lab. Pract. I7, 994.

Demeyer, D. I. \& Henderickx, H. K. (1967). Biochem. F. ro5, 27x.

Emery, R. S., Burg, N., Brown, L. D. \& Blank, G. N., (1964). F. Dairy Sci. 47, I074.

James, A. T. \& Martin, A. T. P. (1952). Biochem. ₹. 50, 679.

Jones, L. R. \& Riddick, J. A. (1957). Analyt. Chem. 29, 1214.

Kluyver, A. J. \& Schnellen, Ch. (1937). Enæymologia 4, 7.

McDougall, E. I. (1948). Biochem, \%. 43, 99.

Ranson, S. L. \& Yeoman, M. M. (I96I),In Biochemists' Handbook p. 958 [C. Long, cditor]. London: E. \& F. N. Spon Ltd.

Scardovi, V. (1960). Ann. Microbiol. ro, 99.

Sijpesteijn, A. K. \& Elsden, S. R. (I952). Biochem. F. 52, 4I.

Takagi, Y. \& Sawada, H. (1964). Biochim. biophys. Acta 92, ro. 